\title{
Desdobramentos dos "olhares" móveis sobre o terrorismo em Londres: como as vítimas viraram repórteres
}

\author{
Eduardo Campos Pellanda ${ }^{1}$ \\ PUCRS \\ edupel@uol.com.br
}

\begin{abstract}
Resumo: No dia 7 de julho de 2005 Londres foi vitima de um série de ataques terroristas que marcaram mais um capítulo da guerra entre culturas ocidentais e orientais. $O$ ineditismo deste dia foi a captura $e$ publicação instantânea dos fatos pelas próprias vitimas com seus aparelhos celulares e não por câmeras caras dirigidas por profissionais da comunicação. A BBC recebeu milhares de vídeos $e$ fotos de pessoas que queriam narrar o que tinham vivido. A tecnologia móvel não só tem permitido o acesso a diversos tipos de conteúdos mas também a publicação instantânea em Moblogs e site de fotos. Toda uma geração de cidadãos repórteres (GILLMOR 2004) começam a surgir alterando o papel de grandes empresas de comunicação em coberturas como esta.
\end{abstract}

\begin{abstract}
In July 7 of 2005 London was vitim of a series of terrorist attacks that had marked a chapter of the war between occidental and eastern cultures. This day was capture with cellular devices and not for expensive cameras directed by professionals of the communication. The $B B C$ received thousand videos and photos of people who wanted to tell what they had lived. The mobile technology has not only allowed to the access the diverse types of contents but also the instantaneous publication in moblogs. All these generation of citizens reporters (GILLMOR 2004) starts to appear modifying the paper of great companies of communication in coverings as this.
\end{abstract}

Resumen: En el julio 7 de Londres 2005 eran vitim de una serie de ataques del terrorista que habían marcado un capítulo de la guerra

\footnotetext{
${ }^{1}$ Doutorando em Comunicação PUCRS
} 
entre las culturas ocidental y del este. Este día era captura con los dispositivos celulares y no para las cámaras fotográficas costosas dirigidas por los profesionales de la comunicación. El BBC recibió mil videos y fotos de la gente que deseó decir lo que él había vivido. La tecnología móvil ha permitido no solamente al acceso los tipos diversos de contenido pero también de la publicación instantánea en moblogs. Todos estos generación de los reporteros de los ciudadanos (GILLMOR 2004) comienzan a aparecer de modificación del papel de grandes compañías de la comunicación en cubiertas como esto.

Resumé: En juillet 7 de Londres 2005 étaient vitim d'une série d'attaques de terroriste qui avaient marqué un chapitre de la guerre entre les cultures occidental et orientales. Ce jour était capture avec les dispositifs cellulaires et pas pour les appareils-photo chers dirigés par des professionnels de la communication. Le BBC a reçu mille videos et photos des personnes qui ont voulu dire ce qu'elles avaient vécu. De la technologie mobile a non seulement permis à l'accès les types divers le contenu mais également la publication instantanée dans les moblogs. Tous ces génération des journalistes de citoyens (GILLMOR 2004) commence à sembler modifiants le papier de grandes compagnies de communication dans les bâches en tant que ceci.

As novas possibilidades da internet móvel estão começando a ser exploradas com maior profundidade, trata-se de um objeto em plena fase de expansão, portanto o quadro sempre será analisado levando em conta esta perspectiva. A questão focal é a analise de potencialidades que se pode detectar no presente, mas como a "potencia” é uma energia latente esta pronta para se manifestar no futuro. Não se trata de fazer previsões infundadas, mas de tentar entender o processo de latência e os possíveis desdobramentos.

Os novos aparatos de comunicação móvel esta alterando tanto produtores como consumidores de conteúdo. A própria questão da fronteira entre estes papeis é um dos pontos centrais desta discussão. Jornalistas estão cada vez mais equipados e cidadãos começam a ter ferramentas de captação e transmissão de conteúdos. GILLMOR (2004) salienta que a BBC já equipou a sua equipe de reportagem com celulares $3 \mathrm{G}$ que podem acessar a Web em alta 
velocidade. O objetivo é que os repórteres possam transmitir entrevistas em vídeo e áudio de qualquer lugar. O ponto de GILLMOR é que exatamente estas ferramentas estão também disponíveis para qualquer cidadão comum.

Para Levinson (2004) existe uma sociedade telepática que é potencializada pelo telefone celular. A comunicação sem contato físico é transformada em troca de mensagens: "A sociedade telepática, em outras palavras, vai dizer respeito a informação não material, e sem a possibilidade do toque." (LEVINSON 2004:61)

A computação de dados somada a comunicação em rede Wireless parece possibilitar a execução de mais tarefas simultâneas, e uma maior eficiência no final do dia. O tempo livre ganho pela rapidez destas execuções nem sempre é utilizado para o lazer, e sim para mais trabalho. O cidadão desta nova sociedade always on está encrustado em maiores possibilidades de rendimento e oportunidades de comunicações. Como potencia latente a tecnologia Wireless pode fazer com que se troque o ambiente do escritório por um que o profissional se sinta mais saudável do ponto de vista criativo como a sua casa ou até mesmo algum lugar afastado da metrópole. Isso na teoria seria cada vez mais possível, questões culturais impedem que isso seja uma realidade. Mas é importante ressaltar a questão latente, as possibilidades. Como toda a tecnologia o uso, o culto, vai determinar a "cultura".

A questão que se levanta diante destes dados é como as pessoas irão se adaptar a este novo ambiente always on? Ou como será a relação com tempo e como será o método de administração do período livre? Pode-se tanto ter mais folgas ao se levar o trabalho para casa como mais trabalho se não for encontrado algum mecanismo de limite. $\mathrm{O}$ cartão ponto, o aceso a equipamentos e documentos exclusivos do ambiente de escritório eram pontos tradicionais de fronteiras entre espaços temporais. Estes não devem ser mais os pontos de referência. A possibilidade de se desligar sempre será possível, mas com impactos cada vez mais profundos: 


\begin{abstract}
"Aqueles que querem somente uma vida simples podem escolher se desplugar, e viver fora do circuito em Idaho. Mas particularmente para este começo-de-século-vinte-um objeto nodular, desconectar pode significar amputar. Eu sou parte das redes, e as redes são partes de mim. Eu apareço nos diretórios. Eu sou visível no Google. Eu conecto, logo existo.” (MITCHELL 2003:62)
\end{abstract}

Retornando a potencia latente deste novo ambiente; a possibilidade existe para todos os lados simultaneamente. É possível facilitar o trabalho, o entretenimento e até mesmo o terrorismo. É latente sair dos escritórios para quem sempre esteve preso como é possível que profissões como repórteres que sempre estiveram nas ruas "voltem" mais rápido para as redações. Para os novos pontos de demarcações sociais novas regras de convívio devem ser desenvolvidas como forma de controle social. Possivelmente haverá mecanismos de desplugar por momentos. Como afirmou o presidente da Motorola, esta é realidade que Teenagers talvez saibam entender melhor as fronteiras entre os elementos sociais.

\title{
Conflitos e situações críticas mediados por celulares
}

A guerra do Iraque em 1991 marcou o primeiro grande conflito ao vivo transmitido ao vivo pela TV. Enquanto caças sobrevoavam Bagdá os repórteres da CNN narravam o fato ao som de explosões. Mais de dez anos depois, em março de 2003, a segunda grande investida das forças ocidentais contra o Iraque os repórteres narravam as cenas de dentro dos tanques (embedded journalists) através de telefones celulares e aparelhos de videofone ligados à satélites. O próximo passo seria a população mostrar de dentro dos conflitos o que aconteceu; foi o que aconteceu em Madrid e Londres durante os ataques terroristas. Vitimas viraram repórteres no meio da desinformação geral que se seguiu aos incidentes.

Muito pouco se sabe sobre o vôo 93 da United Airlines que em 11 de setembro de 2001 caiu em uma zona rural sem atingir nenhum alvo. Mas os nomes de Todd Beamer e Jeremy Glick foram divulgado como heróis pelo FBI. 
Eles se comunicaram pelo celulares com as famílias dizendo que estavam sendo seqüestrados. Logo foram informados que tratava-se de um atentado em grande escala e que provavelmente o avião que eles estavam estaria focando algum alvo. Houve então uma rebelião por parte dos passageiros e o avião acabou caindo sem atingir nenhum ponto. Os celulares foram usados como armas neste caso como saliente Levinson:

\begin{abstract}
"Como mísseis que podem atingir restaurantes em qualquer lugar no mundo em apenas minutos com uma chamada de celular, e eles estão proliferando desta maneira como qualquer arma" (LEVINSON 2003:158)
\end{abstract}

Câmeras em telefones ainda não eram comuns, mas e se fossem? GILLMOR (2004) levanta esta questão: "O que lembraríamos se as pessoas nos aviões e nos edifícios tivesse celulares com câmeras? (GILLMOR 2004:49)

A questão levantada pelo autor não é como seriam as imagens, mas sim, como seriam as nossas lembranças? A TV mostrou várias cenas sem cortes naquele dia que não mais reproduziu. Mas estas imagens estão na Web e nas memórias das pessoas.

Minutos seguintes aos ataques de 11 de setembro ocorreram explosões de informações que começaram a fluir na Web. O espaço virtual norteamericano ficou completamente congestionado enquanto o resto do mundo trocava informações e tentavam entender os acontecimentos. Este fato mostra como o sistema de rede descentralizado que foi projetado para a época da guerra fria funcionou. Um ponto pode estar congestionado que os outros continuam operando. $\mathrm{O}$ acumulo de informações a partir do fato foi um dos grandes testes da Internet:

"Houve um acumulo explosivo de material de testemunhas oculares, reportagens, noticias, análises, sites de memoriais, páginas de tributos, registro de sobreviventes, comentários e analises da policia. Um ano depois, quando os primeiros livros sobre os ataques começaram a surgir, e a discussão da arquitetura do memorial estava somente começando, o arquivo da Internet já continha cinco terabytes de material indexado online sobre o assunto. (Como comparação todo o volume da Biblioteca do 
A informação parecia ser o bem mais valioso nos momentos que se seguiram a tragédia. E ao longo do tempo a Web serviu como suporte para as manifestações de revolta bem como as tentativas de entender o que tinha passado e como seria o mundo dali para diante.

Muitas empresas que não tinham funcionários trabalhando nos prédios e possuíam suas informações descentralizadas puderam rapidamente se recompor e continuaram atuando. Outras que também não tiveram perdas humanas, mas que tinham informações centralizadas em servidores dentro dos escritórios fecharam. Este episódio foi crucial para evidenciar que a história das corporações esta ligada não somente aos profissionais que nela trabalham mas as suas informações em banco de dados. Os bens físicos não podem ser quantizados no patrimônio das empresas da mesma forma que a informação. As ações de empresas ligadas a sistemas de backup subiram muito depois do atentados.

Com as redes de telefonia celular bloqueadas pela quantidade súbita de conexões a forma mais eficiente de se comunicar em movimento foram as mensagens SMS. Este tipo de comunicação pode transitar em linhas congestionadas com muito mais eficiência porque ocupa menos banda do que ligações por voz. Além disso, as mensagens esperam o um momento de descongestionamento para serem enviadas. Este mesmo uso do SMS foi verificado momentos após a tragédia do tsunami na Ásia em 2004.

Em pesquisa realizada em Nova Iorque apos os atentados por CASTELLS, FERNANDEZ-ARDEVOL, QIU \& SEY (2004) mostrou que 43\% dos entrevistados se sentem-se mais seguros com celulares do que sem eles. Alem disso, os pesquisadores relatam que as pessoas estão buscando fornecer celulares para os filhos pelo mesmo motivo. A sensação de segurança é a possibilidade de estar conectado, de estar online com parentes e amigos. A 
mesmo stress que alguns podem sentir por estarem sempre conectados em um ambiente always on pode, mudando o contexto, significar uma alivio.

Nos dias seguintes aos ataques toda a área sul da ilha de Manhatam ficou sem acesso à Internet. O grupo de voluntários ligados a organização NYCWireless ajudou na divulgação de vários pontos de acesso WI-FI para que se pudesse cmpartilhar conexões. Quem possuía redes fechadas rapidamente abriu-as. Exatamente com em locais devastados como o Iraque a comunicação Wireless foi a maneira mais rápida da comunicação, e por conseqüência, e das empresas voltarem a operar.

Em 11 de março de 2004 os atentados ocorridos em Madrid tiveram o telefone celular como ator principal em dois momentos distintos. Este aparelho foi responsável por detonar as bombas² e também por mobilizar a população após os incidentes.

Os celulares formam usados como detonadores de dois modos: o primeiro era usado como controle de detonação remoto e o segundo o aparelho ficava junto com as bombas com alarmes para a detonação. A bomba colocada na estação de El Pozo não detonou porque o celular ali colocado tinha sido colocado com doze horas de atraso.

Por ter sido detectado este mecanismo ficou evidente que não se tratava de atentados do grupo basco ETA $^{3}$. Esta informação em um primeiro momento não agradou ao governo, que estava há três dias da re-eleição. A questão envolvia a política externa do governo Espanhol que estava alinhada com os Estados Unidos em esforços anti-terroristas. Se ficasse evidenciado isto as eleições ficariam prejudicadas, o que acabou acontecendo. Textos de SMS4 formam enviados pela população alertando as pessoas sobre o fato. A rede de comunicação alternativa foi muito mais eficiente do que a mídia

\footnotetext{
${ }^{2} \mathrm{http}: / / w w w . a n s w e r s . c o m / t o p i c / a f t e r m a t h-o f-t h e-11-m a r c h-2004-m a d r i d-a t t a c k s$

${ }^{3} \mathrm{http}: / /$ www.yotor.com/wiki/en/11/11\%20March\%202004\%20Madrid\%20attacks.htm

${ }^{4} \mathrm{http}: / /$ www.smartmobs.com/archive/2005/03/11/march_11_remem.html
} 
impressa e televisiva, que foi usada pelo governo para tentar vender a sua história. O primeiro ministro espanhol chegou a pessoalmente ligar para os editores dos principais jornais para afirmar que tinha sido um ataque do ETA segundo por CASTELLS, FERNANDEZ-ARDEVOL, QIU \& SEY (2004).

Paralelamente mensagens de SMS foram sendo transmitidas para que as pessoas se reunissem em uma passeata no dia seguinte aos atentados para protestar contra a violência. Cada pessoa que recebeu enviava para várias outras, e deste modo, a rede cresceu de maneira exponencial. A manifestação resultante foi a de maior público desde o final da Segunda Guerra Mundial.

Este fenômeno de comunidades se reunirem rapidamente a partir de uma rede de mensagens SMS já tinha sido testado em várias capitais com o nome de FlashMob. As pessoas mandavam mensagens para amigos, que por sua vez mandavam para outros conhecidos e rapidamente uma multidão se reunia em algum lugar, faziam algum tipo de manifestação e rapidamente se dispersavam. O caso de Madrid comprovou a eficiência de redes como a de FlashMobs poderiam ser usadas para outros fins: "Esta forma de comunicação autônoma toca uma sineta para os controles de informações de governos e grande mídia” por (CASTELLS, FERNANDEZ-ARDEVOL, QIU \& SEY 2004:221)

Depois do trágico tsunami que se alastrou por quase toda a costa asiática do Oceano Pacífico, as pessoas se perderam por serem arrastadas pela água e destroços. As antenas de celulares por estarem em regiões mais altas puderam continuar operando, mas a quantidade de ligações era tão imensa que congestionou qualquer tipo de chamada de voz. Como anteriormente mencionado, o uso do SMS foi fundamental para que as pessoas pudessem se comunicar. 
Empresas de telefonia no Sri Lanka mandaram mensagens SMS para a população na tentativa de localizar sobreviventes. Vieram $2.321^{5}$ respostas e algumas pessoas que estavam perdidas foram localizadas.

Além do uso do SMS milhares de sites e Blogs se reuniram no mundo inteiro em uma rede para ajudar a encontrar desaparecidos e proporcionar maneiras de enviar ajuda. Segundo pesquisa realizada por LEMOS \& NOVAS (2005) o uso de tecnologias SMS, WI-FI e Blogs foram peças fundamentais para os esforços pós-tragédia. Segundo os autores doações foram feitas em vários países através das operadoras de telefonia móvel que disponibilizaram sistemas de SMS para o pagamento. Os Blogs foram fundamentais para a divulgação das primeiras fotos e vídeos dos locais das tragédias. Também foram estes os primeiros locais de depoimentos das pessoas que sobreviveram às ondas. O WI-FI, como nos outros casos de desastres, foi fundamental para a implantação de redes de comunicação para os locais atingidos. A ONG “Telécom Sans Frontières” ajudou na construção de redes sem-fio em vários pontos onde não existia formas de acessar a rede.

Em outra tragédia na sociedade ocidental, as bombas na cidade de Londres em 7 julho de 2005, os celulares desempenharam um papel fundamental no esclarecimento e investigação dos incidentes. Pessoas que estavam nas linhas de metrô e nas ruas perto do ônibus onde foi colocado uma das bombas usaram a possibilidade de criar filmes digitais para registrar os acontecimentos como pode ser observado nas figuras abaixo:

\footnotetext{
${ }^{5}$ http://www.smartmobs.com/archive/2004/12/29/tsunami_mobile.html 


\section{(e) compós}

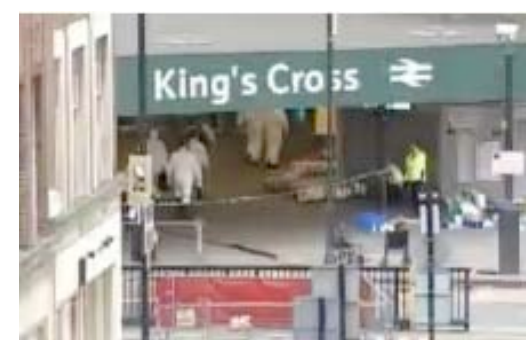

Fig. 7

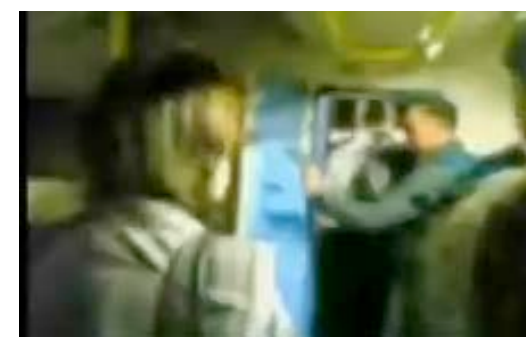

Fig. 9

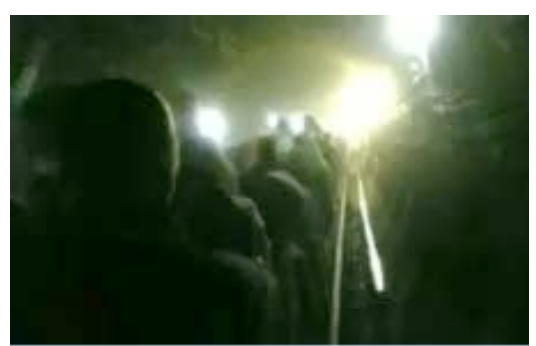

Fig. 8

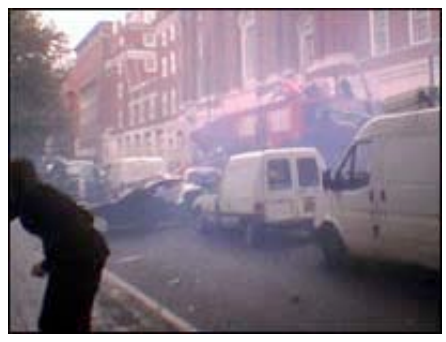

Fig. 10

Os quadros foram reproduzidos do vídeo que a $\mathrm{BBC}^{6}$ montou a partir de algumas mensagens recebidas pela empresa. A BBC manteve um número para que as pessoas que captaram imagens pudessem mandar. Cerca de 1.000 fotos e 20 vídeos chegaram a redação da BBC minutos após os acidentes. Uma das fotos enviadas pelo publico foi o principal destaque da capa durante a maior parte do dia.

Os registros foram os únicos realizados nos locais dos acidentes minutos depois das explosões. Tanto do ponto de vista de material jornalístico como para investigações policiais o material foi fundamental. A qualidade das imagens já são capazes de mostrar detalhes importantes. As câmaras em celulares estão chegando neste ano a vários megapixels e o aumento de qualidade tende em alguns anos a se aproximar da qualidade de transmissão broadcast. Além disso, o número de vendas de cululares com câmera

\footnotetext{
${ }^{6} \mathrm{http}: / /$ news.bbc.co.uk/1/hi/technology/4663561.stm
} 
ultrapassou os aparelhos sem o recurso de captar imagens7. Isso, ampliará o poder que cada cidadão terá para registrar momentos como este. Mas, no caso de Londres a qualidade ficou em segundo plano. O conteúdo inédito e precioso foi o principal foco de ineditismo para o acontecimento.

A previsão de GILLMOR (2004) estava correta com relação ao usos das câmeras conectadas: "Amanhã telefones móveis vão ser capazes de enviar informações para indivíduos e grupos, e publicar em páginas da Web perto do tempo real" (GILLMOR 2004:35)

Sites que hospedam fotos enviada por celulares gratuitamente como o Flickr ${ }^{8}$ foi também o destino final do material. A partir do Flicker é possível também inserir as fotos em Blogs. Empresas como a BBC serviram como grande referencia para as notícias, mas os usuários também tiveram a independência de publicar em seus próprios sites e Blogs.

Em relação ao tráfego de usuários da $\mathrm{BBC}$, este bateu o recorde de acessos durante as 24 horas posteriores ao incidente, foram 115 milhões 9 de page views. Este numero representou $28,6 \%$ de todo os acessos do Reino Unido. Foi montado um esquema especial coma rede de distribuição de banda Akamai para que se pudesse dar conta de todo o fluxo de acesso.

A Internet foi responsável por grande parte do foco de atenções depois dos acidentes. O site Technorati, responsável por averiguar o movimento dos Blogs, detectou $1.300^{10}$ posts sobre o incidente por volta das 10h:15min GMT. Além disso, um site islâmico colocou minutos depois que o al-Qaeda estava reinvidicando o atentado. Estes acontecimentos foram também responsáveis pelos números de acessos ao site da BBC. As pessoas acompanhavam o desenrolar dos acontecimentos acessando várias vezes o site da empresa pública britânica.

\footnotetext{
${ }^{7}$ Dados revista Exame edição 844 - 8/junho/2005

${ }^{8}$ www.flickr.com

${ }^{9} \mathrm{http}: / /$ news.bbc.co.uk/1/hi/technology/4672869.stm

${ }^{10} \mathrm{http}: / /$ news.bbc.co.uk/1/hi/technology/4659679.stm
} 
Pode-se perceber neste caso que a Internet e os meios móveis estão desempenhando um novo papel neste mutante ambiente midiático. Em nenhum meio anterior era possível ter a versão dos dois lados de um conflito com relatórios oficiais e depoimentos de cidadãos que vivenciaram o fato ou que querem se manifestar sobre o assunto.

O cidadão repórter (GILLMOR 2004) agora capta tudo de publica tudo o que vê. O jornalo londrino The Guardian proclamou este acontecimento como "o verdadeiro nascimento do cidadão repórter"11. A câmera no celular não á mais simplesmente a possibilidade de tirar fotos, mas sim uma máquina de publicação instantânea. Foto e vídeos de amadores não são novidades, mas a coincidência de ter algum cidadão com uma câmera em um dado acontecimento tornou estes eventos raros no passado. As câmaras nos celulares estão se popularizando de modo a ser cada vez mais provável que quando aconteça algum incidente alguém possuir alguma forma de registrá-lo.

Outro ponto de mudança cultural é sobre a comercialização deste material. Enquanto uma das primeiras providências de quem possuía algum tipo de material amador sobre incidentes procuram os grandes conglomerados de mídia para tentar vender a exclusividade da imagem. No episódio de Londres as imagens chegaram no email da BBC gratuitamente ${ }^{12}$. Isso pode ter ocorrido por ter tido um grande numero de pessoas registrando o mesmo incidente, pela vontade dos cidadãos de ajudar na investigação ou então pela consciência de que a BBC é uma empresa pública. Novas experiências em outros contextos poderão apontar para possíveis mudanças neste comportamento.

Claro, que há espaço para censura e tentativa das grandes instituições sociais controlar este ambiente como qualquer outro que já existiu na história.

\footnotetext{
${ }^{11} \mathrm{http}: / /$ www.smartmobs.com/archive/2005/07/14/londons_swarm_.html

$12 \mathrm{http}: / /$ www.wired.com/news/technology/0,1282,68143,00.html
} 
O governo inglês esta tentando tirar do $\operatorname{ar}^{13}$ todos os sites dentro do Reino Unido que estejam incitando o terrorismo. O problema é que nem todos os sites estão hospedados no Reino Unido e, deste modo, a interrupção da publicação torna-se quase impossível. Neste ambiente sem fronteiras geográficas as regras são inéditas, e governos não tem a mesma rapidez de mudança.

Fotos e vídeos são transmitidos de lugares remotos das cidades para mobilogs ou mesmo para outras pessoas e para empresas de comunicação com o caso dos registros aos atentados de Londres enviados diretamente para a BBC. São cidadãos repórteres (GILLMOR 2004) que possuem ferramentas de captura de informações e o ambiente de rede para distribuí-las. As redes wireless funcionam em duas vias e potencializam o canal de retorno do público ajudando a deslocar o centro de emissão de informações das mídias tradicionais composta necessariamente por grandes empresas.

\section{Referências:}

CASTELLS, M., FERNANDEZ-ARDEVOL, M., QIU, J. L., \& SEY, A., The Mobile Communication Society, A cross-cultural analysis of available evidence on the social uses of wireless communication technology, Documento online:

http://annenberg.usc.edu/international_communication/WirelessWorks hop/MCS.pdf, (2004)

GILLMOR, Dam. We the Media - Grassroots by the people, for the people, Sebastopol, O’ Reilly Media, 2004

LEVINSON, Paul. Cellphone, New York, Palgrave, 2004

MITTCHELL, William J. ME++, The Cyborg Self and the Networked City, Boston, MIT Press, 2003

RHEINGOLD, Howard. Mobile Virtual Communities. Boston,MIT Press, 2001

-- . Smart Mobs. Cambridge, Perseus Publishing, 2003

-- . Moblogs Seen as a Crystal Ball for a New Era in Online Journalism, USC online Journalism Review (http://www.ojr.org/ojr/technology/1057780670.php), 2003

\footnotetext{
${ }^{13} \mathrm{http}: / /$ news.com.com/U.K.+to+crack+down+on+terrorist+sites/2100-7348_35798787.html?tag=nefd.top
} 